\title{
階層分析法とシミュレーションによる CRシステム導入の評価要因の検討
}

\author{
横岡由姫・小笠原克彦1) \\ 医療法人社団三草会クラーク病院放射線科 \\ 1 ) 北海道大学医学部保健学科
}

\section{はじめに}

臨床の放射線科領域において画像診断機器は必須 である。しかし，画像診断機器は高価であり，機器 の選定にあたっては装置の性能や収益などの評価要 因が複雑に絡み合っており，導入基準や評価要因は 曖昧といってもよいであろう。さらに，過去に画像診 断機器の画質や性能に関する研究は数多く行われて いるが，導入時の選定に関する研究は行われていな いのが現状である。

階層分析法 (analytic hierarchy process : AHP) は米 国ピッツバーグ大学のサーティ教授により提唱され た。医学・医療の分野では, 病院の救急部における 救急患者への処置の優先度の決定や特定の疾患に対 し投薬する薬の選定などで使用されており，その応 用範囲は広い1 12).
本研究では, computed radiography (以下, CR)の 導入について, 適切な機器選択のための医療機関の 環境に応じた画像診断機器の導入基準を明確にする ことを目的として, 以下を分析した。 (1) 従来の階層 分析法による機器選択, (2) シミュレーションによる 導入決定に与える影響.

\section{1. 方 法}

\section{1-1 評価要因の定義とモデルの構築}

$\mathrm{CR}$ 導入の評価基準は, $\mathrm{CR}$ 導入を予定している 3 医療機関 (環境・規模・被検者の個性などのばらつき を最小限とするために同規模)に勤務する放射線技師 経験 5 年以上の放射線技師 3 名によってISM (interpretive structural modeling)法により抽出された以下 の 7 評価要因 ${ }^{13)}$ を使用した.

\section{Evaluation Factors for CR System Introduction Using AHP and Simulation Yuki Yokooka, and Katsuhiko Ogasawara')}

Department of Radiological Technology, Clark Hospita

1 ) Department of Health Sciences, School of Medicine, Hokkaido University

Received Nov. 1, 2007; Revision accepted June 5, 2008; Code Nos. 920, 990

\section{Summary}

Medical institutions usually find it difficult to select computed radiography (CR) equipment because of the involvement of many complicated factors such as operability, processing time, and price. The analytic hierarchy process (AHP) is often applied in complex decision and evaluation situations. This study quantitatively evaluates the institution's selection criteria of equipment using AHP. The AHP model of this study consisted of 3 levels: the goal, 6 evaluations, and 3 alternatives. Processing time, price operability, picture quality, connectivity, and equipment size were considered as the criteria for decision marking. We simulated alteration of priority of evaluations by changing the weight of pricing between 0 and 1 . Results showed that price and connectivity accounted for $60 \%$ of the total weight. On excluding operability, the difference in weight between equipment was 1.16 times; the priority of processing time was 1.36 times; and the priority of price was 1.37 times. In the same way, when considering operability, the difference in weight between equipment was 0.36 times, the priority of processing time was 0.45 times, and the priority of price was 0.11 times.

Key words: CR (computed radiography), AHP (analytic hierarchy process), simulation, evaluation factor

別刷資料請求先：干060-0812 北海道札幌市北区北12条西 5 丁目

北海道大学医学部保健学科 小笠原克彦 宛 


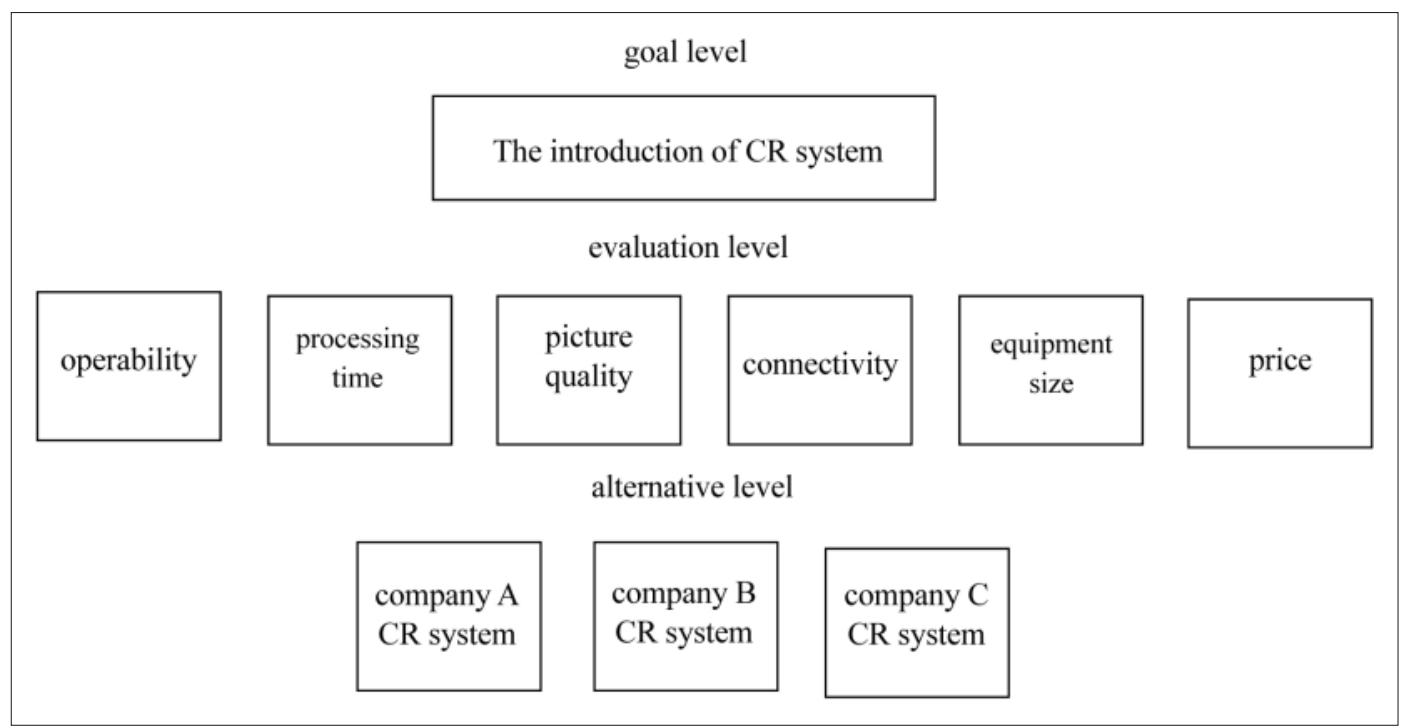

Fig. 1 Model of the introduction of the CR system.

Table 1 Evaluation matrix.

\begin{tabular}{lccc}
\hline \hline & \multicolumn{3}{c}{ CR system } \\
\cline { 2 - 4 } & Company A & Company B & Company C \\
\hline picture quality & $12 \mathrm{bit} / 87.5 \mu \mathrm{m}$ & $12 \mathrm{bit} / 100 \mu \mathrm{m}$ & $12 \mathrm{bit} / 100 \mu \mathrm{m}$ \\
connectivity & + & + & - \\
equipment size & $0.89 \mathrm{~m}^{3}$ & $0.29 \mathrm{~m}^{3}$ & $0.72 \mathrm{~m}^{3}$ \\
\hline
\end{tabular}

操作性(装置を操作しやすい), 処理時間(画像の処 理時間が短い)，画質(最低の画質が保証されてい る), 保存性(画像の保存に場所をとらず複製が可能 である), 接続性(HIS・PACSへの接続が可能であ る), 大きさ(装置が小さく場所をとらない), 価格(本 体の価格が安い)。ただし，保存性については先行研 究での評価要因の抽出当時は各代替案の機器の性能 に差があったが，現在は技術進歩によりどの機種も 同等の性能であるため本分析では影響がないと考え 削除し，6 要因とした。この 6 評価要因に基づき, Fig. 1に示すようにCR導入モデルを定義した。目的層 を「CRシステムの導入」とし, 評価基準層を「導入決 定要因」, 代替案層を「導入機器」とした.

\section{1-2 階層分析法による分析}

定義された評価要因の重要性を一対比較法により 決定した。評価要因の評価は, シミュレーションとし て著者自身が行った。重要性の尺度には $1 ， 3 ， 5$, 7，9の奇数を用いて順に「同じ位重要」「少し重要」 「かなり重要」「非常に重要」「極めて重要」とした。一 方, 個々の評価要因が重要でないと判断された場合
はその逆数である $1 / 3 ， 1 / 5,1 / 7,1 / 9$ 順に「少し重要 でない」「かなり重要でない」「非常に重要でない」「極 めて重要でない」とした。 また, 重要性がこれらの数 值の中間の場合は中間值である偶数を用いた。

次にその決定した重みについて，以下の式により 整合度を計算した。整合度とは，評価者による意図 的なバイアスや, 評価の首尾一貫性など評価の矛盾 を判断するものである。

整合度 $=\left(\lambda_{\max }-\mathrm{n}\right) /(\mathrm{n}-1)$

ここでnは評価要因の数, $\lambda_{\max }$ は行列式の固有べク トルの最大值とし，整合度が 0.1 以下を有効とした。

なお，解析には文献14）に添付されていたソフト ウェアを使用した。

1-3 シミュレーション

代替案の重みの決定は, 各社の製品パンフレット に記載されている数值 (Table 1)をもとに算出した。 た たし，操作性・処理時間・価格についてはパンフ レットより得られなかったため, これらの評価要因に ついては，以下のシミュレーションを行った。 
Table 2 Comparison of alternatives.

\begin{tabular}{lcccccc}
\hline \hline & operability & $\begin{array}{c}\text { processing } \\
\text { time }\end{array}$ & $\begin{array}{c}\text { picture } \\
\text { quality }\end{array}$ & connectivity & $\begin{array}{c}\text { equipment } \\
\text { size }\end{array}$ & price \\
\hline operability & 1 & $1 / 3$ & $1 / 5$ & $1 / 3$ & 3 & $1 / 3$ \\
processing time & 3 & 1 & $1 / 3$ & 1 & 9 & 3 \\
picture quality & 5 & 3 & 1 & 1 & 7 & 5 \\
connectivity & 3 & 1 & 1 & 1 & 7 & 3 \\
equipment size & $1 / 3$ & $1 / 9$ & $1 / 7$ & $1 / 7$ & 1 & $1 / 8$ \\
price & 3 & $1 / 3$ & $1 / 5$ & $1 / 3$ & 8 & 1 \\
\hline weight & 0.062 & 0.207 & 0.355 & 0.236 & 0.026 & 0.114 \\
\hline
\end{tabular}

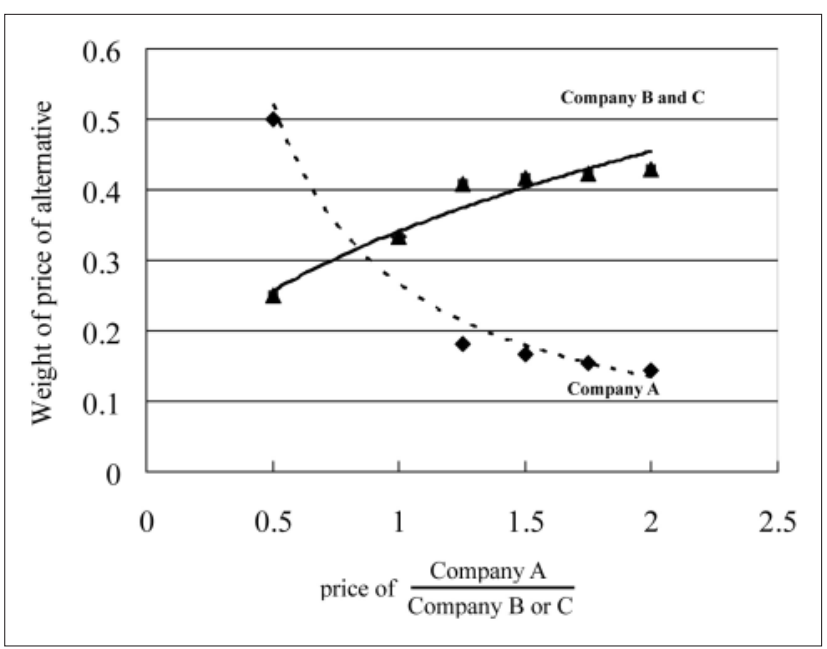

Fig. 2 Change in the weight of the evaluation factor.

\section{1-3-1 シミュレーション 1 (代替案「価格」の重み の変化}

$\mathrm{A}$ 社の $\mathrm{B}$ 社・ $\mathrm{C}$ 社に対する価格の比率を 0.5 から 2 倍 まで変化させ,「価格」の重みの変化を分析する.

1-3-2 シミュレーション 2 (評価要因の感度分析)

$\mathrm{A}$ 社の操作性 - 処理時間 - 価格の各評価要因の重 みの比率を 0 から 1 まで変化させ, 代替案の重みの 変化を分析する。

\section{2. 結 果}

一対比較法により各評価要因の重み付けを行った 結果をTable 2に示す. 6 評価要因のなかで最大が「画 質」(重み：0.355)であった。一方，最小が「大きさ」 （0.026）であった，整合度は，0.081であり，評価に矛 盾はないと判断された.

Fig. 2にシミュレーション 1 の結果を示す.A社の

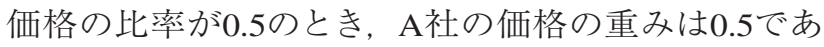

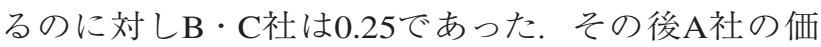
格の比率が増加するにつれA社の価格の重みは減少 したが逆にB・C社の価格の重みは増加し, $\mathrm{A}$ 社の価

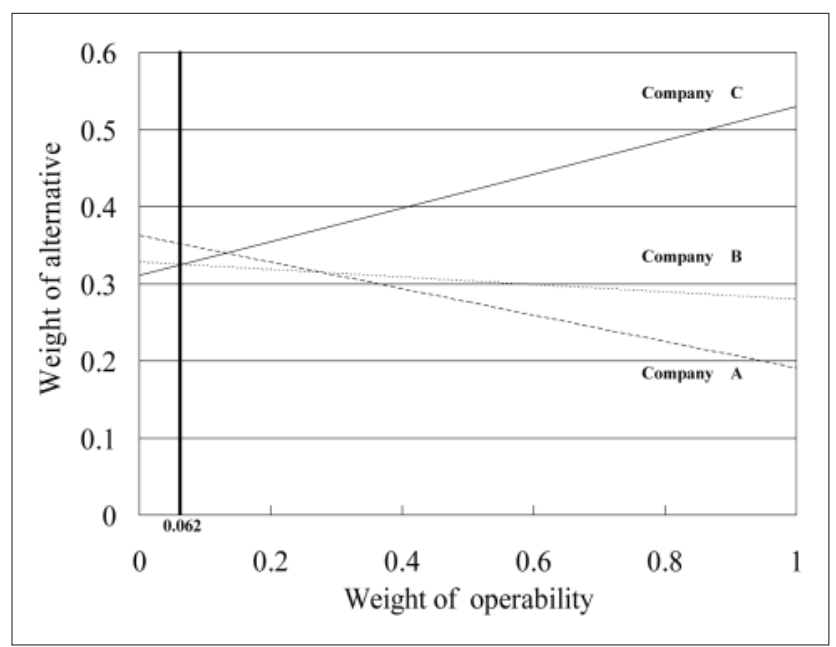

Fig. 3 Simulation of operability.

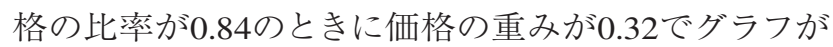
逆転した。

Figs. 3〜5にシミュレーション 2 の結果を示す. 操 作性の検討では, 評価層に扮ける操作性の重みが 0 (操作性を全く無視)の場合のA社の代替案の重みは 一番小さいC社の代替案の重みに比べ1.16倍となった のに対し, 評価層における操作性の重みが 1(操作性 のみを重視)の場合，A社はC 社に対し0.36倍となり代 替案の重みが逆転した，処理時間の検討では，評価 層に扔ける処理時間の重みが 0 の場合のA社の代替 案の重みは一番小さいC社の代替案の重みに比べ1.36 倍となったのに対し, 評価層における処理時間の重 みが 1 の場合はA社はC社に対し0.45倍と, 操作性と 同様に代替案の重みが逆転した。価格の検討では, 評価層に扔ける価格の重みが 0 の場合のA社の代替 案の重みは一番小さいC社の代替案の重みに比べ1.37 倍となったのに対し, 評価層における価格の重みが 1 の場合はA社はC社に対し0.11倍と,「操作性」および 「処理時間」と同様に代替案の重みが逆転した。 


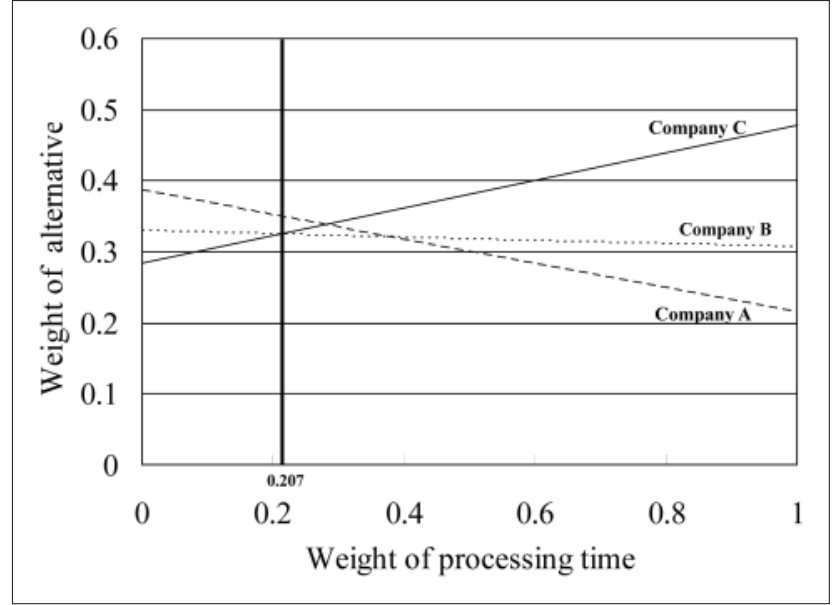

Fig. 4 Simulation of processing time.

\section{3. 考 察}

一対比較法により各評価要因の重み付けを行った 結果, 6 評価要因の中で「画質」が一番大きく, その重 みも全体の1/3であった，次いで，接続性であり，1/4 の重みであった， 6 要因のうち，この 2 要因で全体の ほぼ60\%を占めている。放射線業務を遂行するうえ で画質と接続性は放射線診療に直結しており, 機器 選定を行う際の判断基準として重要といえよう。ま た，「大きさ」および「操作性」については，重みが低 かった。この理由として, これから導入を計画してい る医療機関の放射線技師にとっては，使用経験のな い機器については, 導入後の使用環境や放射線技師 の労働負担を含めた評価が難しいのではないかと推 測される。これらの結果から, 今回の評価結果は導 入の評価要因であるが，実際には導入を希望する放 射線技師の希望が強く現れた可能性があると考えら れる。

「価格」以外の要因が等しい場合について，「価格」 を変化させたシミュレーション 1 を行った結果, 価格 差が小さいと重みの変化が大きいことが明らかになっ た。また，「操作性」処理時間」「価格」の 3 要因の感 度分析であるシミュレーション 2 を行った結果, 「価 格」の重みの変化がCR機器の選択に大きく影響を及 ぼすことが明らかになった。今回，ブランドや過去の 取引における信頼関係などの要因については一切考 慮していないため, 今回の結果から断言することは難 しいが，これらの要因を無視できるのであれば「価格」 の影響は大きいと考えられる。

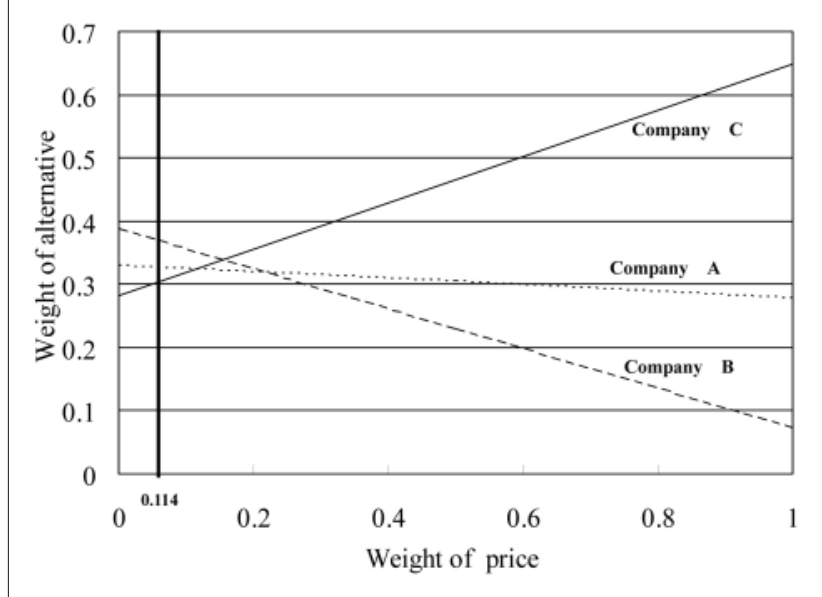

Fig. 5 Simulation of price.

階層分析法の特徵として, 評価要因層の重みを変 えることで評価要因ごとの重みの変化や代替案ごと の重みの変化を数值化し, 曖昧な個人の意思を順位 化することが可能であることが挙げられる1,12,13). 階 層分析法とシミュレーションを用いた本研究におい て，特定の要因の重みを変化させることによって，視 覚的に推奨する機器を明示することが可能であっ た．実際に導入した後でしか判断できない要因につ いて, 事前に機器導入後の状況を客観的に予測する ことが可能であるため，放射線部門運営におけるさま ざまな状況に応じた意思決定のための判断基準とし て，今後これを活用することができると考える。

\section{4. まとめ}

今回， CR機器導入のための評価要因を検討するた めに, 一対比較法とシミュレーションによる分析を 行った。その結果，以下の 3 点が明らかになった。

1) $\mathrm{CR}$ 導入する際の 6 評価要因の中で,「画質(重 み：0.355)」の影響が一番大きく, 次いで接続性 (0.236)であり, この二つの要因で 6 割の重みを占 めていた。

2) 代替案選択のための 2 種類のシミュレーションを 行った結果，「価格」の変化に対する影響が大きい ことが明らかになった。

3）階層分析法とシミュレーションにより評価要因と代 替案を検討した結果, 不確定な状況での選択基準 を推測することが可能であった。 


\section{参考文献}

1) Dolan JG, Isselhardt BJ Jr, Cappuccio JD. The analytic hierarchy process in medical decision making: a tutorial. Med Decis Making 1989; 9(1) : 40-50.

2) Dolan JG. Can decision analysis adequately represent clinical problems? J Clin Epidemiol 1990; 43(3) : 277-284.

3) Ross ME, Nydick RL. Selection of licensing candidates in the pharmaceutical industry - An application of the analytic hierarchy process. J Health Care Mark 1992; 12 (2) : 60-65.

4) Hatcher M. Voting and priorities in health care decision making, portrayed through a group decision support system, using analytic hierarchy process. J Med Syst 1994; $18(5): 267-288$

5) Koch T. Normative and prescriptive criteria-The efficacy of organ transplantation allocation protocols. Theor Med 1996; 17 (1) : 75-93.

6) Kwak NK, McCarthy KJ, Parker GE. A human resource planning model for hospital/medical technologists - An analytic hierarchy process approach. J Med Syst 1997; 21 (3) : 173-187.

7) Kahen G, Sayers BM. Health-care technology transferExpert and information systems for developing cuntries.
Methods Inf Med 1997; 36(2): 69-78.

8) Koch T, Ridgley M. Distanced perspectives-AIDS, anencephaly, and AHP. Theor Med Bioeth 1998; 19(1) : 47-58.

9) Carter KJ, Ritchey NP, Castro F, et al. Analysis of three decision-making methods: a breast cancer patient as a model. Med Decis Making 1999; 19(1): 49-57.

10）松田晋哉, 筒井由香, 高島洋子，地域高齢者のいきがい 形成に関する要因の重要度の分析. 日本公衆衛生雑誌 $1998 ；$ 45(8)：704-712.

11）松田晋哉. 階層分析法(AHP)を用いた今後の保健所保健 婦活動の方向性に関する分析. 産業医科大学雑誌 $1998 ; 20(3): 189-199$

12）小笠原克彦，高橋秀樹，平川 昌，他. 階層分析法による 検診用胃バリウム製剤の選択基準に関する検討。日放技 学誌 $1999 ； 55(4) ： 392-396$

13) Ogasawara K, Yamashina $H$, Kamiya $T$, et al. Interpretive Structural Modeling for introducing of image information system at the middle-scale hospitals. AMIA Annu Symp Proc 2003: 957.

14）杉山和雄, 井上勝雄 編. EXCELによる調査分析入門一企 画・デザインのためのツール集，東京：海文堂，1996.

Fig. 1 CRシステム導入モデル

Fig. 2 評価要因の重みの変化

Fig. 3 操作性のシミュレーション

Fig. 4 処理時間のシミュレーション

Fig. 5 価格のシミュレーション

Table 1 評価要因の比較マトリックス

Table 2 代替案の比較 